\title{
Research on Fabrication of Flame Retardant Nanocomposite Coating to Protect Steel Structures on Epikote 240 Epoxy Resin Base with the Synergy of MWCNTs and Fly Ash
}

\author{
Tuan Anh Nguyen \\ Faculty of Chemical Technology, Hanoi University of Industry (HaUI), No. 298, Cau Dien Street, Bac Tu Liem District, \\ Hanoi, Vietnam \\ Correspondence should be addressed to Tuan Anh Nguyen; anhnt@haui.edu.vn
}

Received 23 March 2021; Revised 29 April 2021; Accepted 20 May 2021; Published 1 June 2021

Academic Editor: Witold Kwapiński

Copyright (C) 2021 Tuan Anh Nguyen. This is an open access article distributed under the Creative Commons Attribution License, which permits unrestricted use, distribution, and reproduction in any medium, provided the original work is properly cited.

The use of industrial wastes such as thermal power plant fly ash can reduce the environmental risk. The fly ash properties are useful and can contribute to organic coatings. This paper examines a new strategy for coatings that protect steel structures from the effects of fire while enhancing mechanical properties. The aim of this study was to show that the fly ash additive can be a partial replacement for other conventional additives while also having a flame retardant effect. To study the effectiveness of the use of fly ash additives, we have sought to combine them with nanoadditives. Specifically, we study the synergy of fly ash with multi-wall carbon nanotube additives to reinforce the coating on the system: epoxy Epikote 240/ammonium polyphosphate (APP)/pentaerythritol (PER), and melamine. Content of fly ash was studied: $10 \mathrm{wt} . \%$ with $0.5,1$, and $1.5 \mathrm{wt} . \%$ of multi-wall carbon nanotubes (MWCNTs). The results prove that the synergies between fly ash and multi-wall carbon nanotubes increase the fire resistance to increase the protection of steel structures of the building. When using $10 \mathrm{wt} . \%$ fly ash and $1 \mathrm{wt} . \%$ MWCNTS, the coating can be considered as a flame retardant material with UL $94 \mathrm{~V}-0$ fire resistance and the limiting oxygen index of $27.2 \%$.

\section{Introduction}

Steel is widely used in the world. However, steel with the deterioration of its external structure due to the attack of chemicals and environment is also threatened by fire. Previous studies have shown that steel structures can maintain strength below or up to a maximum temperature of $500^{\circ} \mathrm{C}$. The structure is broken down at a higher temperature. Therefore, to ensure the safety of the steel structure, the temperature of the steel structure must be kept below $500^{\circ} \mathrm{C}$ in the event of a fire incident $[1-3]$. Applications of organic coatings as one of the methods of protecting steel structures in industrial civil engineering are appropriate and established. This coating promotes active protection against corrosion, electrochemical, and other effects of the normal climate. Fly ash, an environmentally friendly additive that has been studied, is one of the flame retardants for polymers. The amount of fly ash that has been studied and put into epoxy resin is $10,20,30,40,50,60$, and 70 percent by weight to make composite materials with fire resistance [4]. Research results have shown that $20 \mathrm{wt} . \%$ fly ash has good mechanical properties and flame retardation. Fly ash is studied as a filler and has flame retardant properties for composite materials based on epoxy resin $[5,6]$. In addition, fly ash is also being studied as an additive to composite materials as insulating materials with the optimum content of $40 \mathrm{wt} . \%$ $[7,8]$. On the other hand, multi-walled carbon nanoadditive has been researched by many scientists around the world to manufacture flame retardant materials. The results showed that with only $0.02 \mathrm{wt} . \%$ MWCNTs dispersed in epoxy resin the flame retardation was significantly improved, and mechanical properties improved $[9,10]$. Nikolas Sabbattini has studied a paint containing clay or plaster to cover theaters in Italy is fire resistant. In 1820, the author Fuchs used nattri silicate over the wood in the Munich theater to protect the wood from the impact of the fire [11]. In $200 \mathrm{BC}$, the Romans used a mixture of alum and vinegar (Potassium Aluminum Sulfate 
$\mathrm{KAl}\left(\mathrm{SO}_{4}\right)_{2} \cdot 12 \mathrm{H}_{2} \mathrm{O}$ or ammonium aluminum Sulfate $\left.\mathrm{NH}_{4} \mathrm{Al}\left(\mathrm{SO}_{4}\right)_{2} \cdot 12 \mathrm{H}_{2} \mathrm{O}\right)$ to coat and impregnate wood [11]. Scientist Obadiah Wyld used a mixture of alum, iron sulphate, and borate salt to reduce the flammability of textiles used for theater and public works, patented in England in 1935 [12]. The flame retardant coating is based on the swelling mechanism studied in 1970 [13]. Its coating provides a thick protective layer to the flame by decomposition at high temperature forming an insulating coal layer. The swollen coating consists of a mixture of pentaerythritol and melamine in the plastic substrate at a low temperature and will expand when thermal decomposition forms an insulating coal layer at a temperature of about 280$300^{\circ} \mathrm{C}$. This carbon layer will act as a thermal barrier and prevent the fire heat from being transferred to the protected material substrate [14]. Guo-Qiang et al. researched fabricating coating films based on ammonium polyphosphate (APP), pentaerythritol (PER), and melamine on polymer base. When burned, at a temperature of $100-250^{\circ} \mathrm{C}$, the acidifying agent in the coating will decompose, reacting with a carbonization agent (PER) to create a coal layer. At temperatures of $280-350^{\circ} \mathrm{C}$, the melamine in the decomposed coating releases a large amount of gas, which expands the coal layer to form an inflated layer of coal that separates the fire heat in contact with the protected substrate [15].

Siqi Huo et al. studied P-containing flame retardants and their effect on the fire resistance, thermal stability, and mechanical properties of epoxy resins. The research team pointed out important future directions for the use of phosphoruscontaining flame retardants $(\mathrm{P})$. Phosphorus $(\mathrm{P})$ flame retardant is one of the substances used a lot in the past for epoxy resins, because it provides a high flame retardant effect [16]. The combination of conventional nanomaterials and flame retardants, either through chemical or physical methods, allows for adjustable mechanical and flame retardant performance, with a tendency to improved properties. Wentao He et al. have studied combinations of nanomaterials and conventional flame retardants containing phosphorus, nitrogen, or silicon. And the results showed that the combination gave good mechanical properties and resistance to fire [17]. In general, nanofillers have been considered as good candidates for a flame retardant additive. Currently, montmorillonite (MMT) and carbon nanotubes (CNT) are the most widely used fillers, because they improve not only their flame retardant properties but also mechanical properties [18-21]. The thermal decomposition and combustion of polymer nanomaterials is a complex physical and chemical process. The fire resistance of nanosynthetic polymers is affected by many factors. One of the important factors is the dispersion of the nanoadditive in the resin matrix. Part of the improved fire resistance is due to the nanotube carbon well dispersed in the resin substrate. MWCNTS forms a thick ash layer on the surface of the material, preventing the burning material from being exposed to heat and oxygen in the air [22-25].

In this study, we focus on thermal power plant waste containing aluminum and silica as fly ash combined with nanoadditive. The aim of this study is to explore the potential of fly ash as an eco-friendly additive combined with a multi-wall carbon nano reinforcement over conventional flame retardant systems.

\section{Materials and Methods}

\subsection{Materials}

Curing agent: LUCKAMIDE Polyamine N-153-IM-65 (Sigma-Aldrich Viet Nam).

MWCNTs with a diameter of 40-45 $\mathrm{nm}$ and a length of around $3 \mu \mathrm{m}$ was provided by Showa Denko Japan Co.

Boric acid (BA), Ammonium polyphosphate (APP), Melamine were purchased from Sigma.

Epoxy Epikote 240 (EP) resin of Shell Chemicals (USA) (see Table 1).

PER: pentaerythritol (2, 2-bis (hydroxymethyl)-1,3propanediol) was provided by Sigma-Aldrich Vietnam (Vietnam).

Fly ash is collected from Pha Lai thermal power plant (Vietnam), with properties as shown in Table 2.

\subsection{Methods}

2.2.1. Sample Preparation. All intumescent ingredients were mixed with their respective weight percentage as stated in Table 3. Technological condition is stirring speed $2000 \mathrm{rpm}$, stirring time is 90 minutes, and 90 minutes ultrasonic vibration. A structural steel plate measuring $100 \mathrm{~cm}^{2}$ was used as the substrate.

\subsubsection{Analysis}

\section{(1) Fire Retardant Evaluation Method}

Limiting Oxygen Index (LOI) according to JIS K720 standard (Japan): the sample bars used for the test were $150 \times 6.5 \times 3 \mathrm{~mm}^{3}$.

The horizontal burning tests (UL-94HB): standard bar specimens are to be $125 \pm 5 \mathrm{~mm}$ long by $13.0 \pm 0.5 \mathrm{~mm}$ wide, and provided in the minimum thickness and 3.0 $(-0.0+0.2) \mathrm{mm}$ thick (ASTM D635-12).

Vertical burning test: UL $94 \mathrm{~V}$, the standard bar samples shall be $125 \pm 5 \mathrm{~mm}$ long $x 13.0 \pm 0.5 \mathrm{~mm}$ wide and supplied in the minimum and maximum thicknesses. The maximum thickness does not exceed $13 \mathrm{~mm}$ (ASTM D635-12).

(2) Method of Determining the Mechanical Properties of the Coating

Impact resistance: determined according to ASTM2794 on Erichsen tool model-304.

Relative hardness: determined according to ISO-1522 on Erichsen tool model 299.

Expansion pressure: determined according to ISO 1520-1973 (E) on Erichsen device model 200. 
TABle 1: Properties of epoxy Epikote 240 resin.

\begin{tabular}{lccc}
\hline Property & Test method & Unit & Value \\
\hline Epoxy group content & SMS 2026 & $\mathrm{mmol} / \mathrm{kg}$ & $5100-5400$ \\
Epoxy molar mass & & $\mathrm{G}$ & $185-196$ \\
Viscosity at $25^{\circ} \mathrm{C}$ & ASTM D445 & Pa.s** & $0.7-1.1$ \\
Colour & ASTM D1209 & Pt-Co & $200 \mathrm{max}$ \\
Density at $25^{\circ} \mathrm{C}$ & ASTM D4052 & $\mathrm{kg} / \mathrm{L}$ & 1.12 \\
\hline
\end{tabular}

${ }^{*}$ No. of grams of resin containing 1g-equivalent of epoxide (weight per equivalent, WPE, is an alternative term). ${ }^{* *} 1$ Pa $s=10$ poise.

TABLE 2: Chemical composition and morphological structure of fly ash [26].

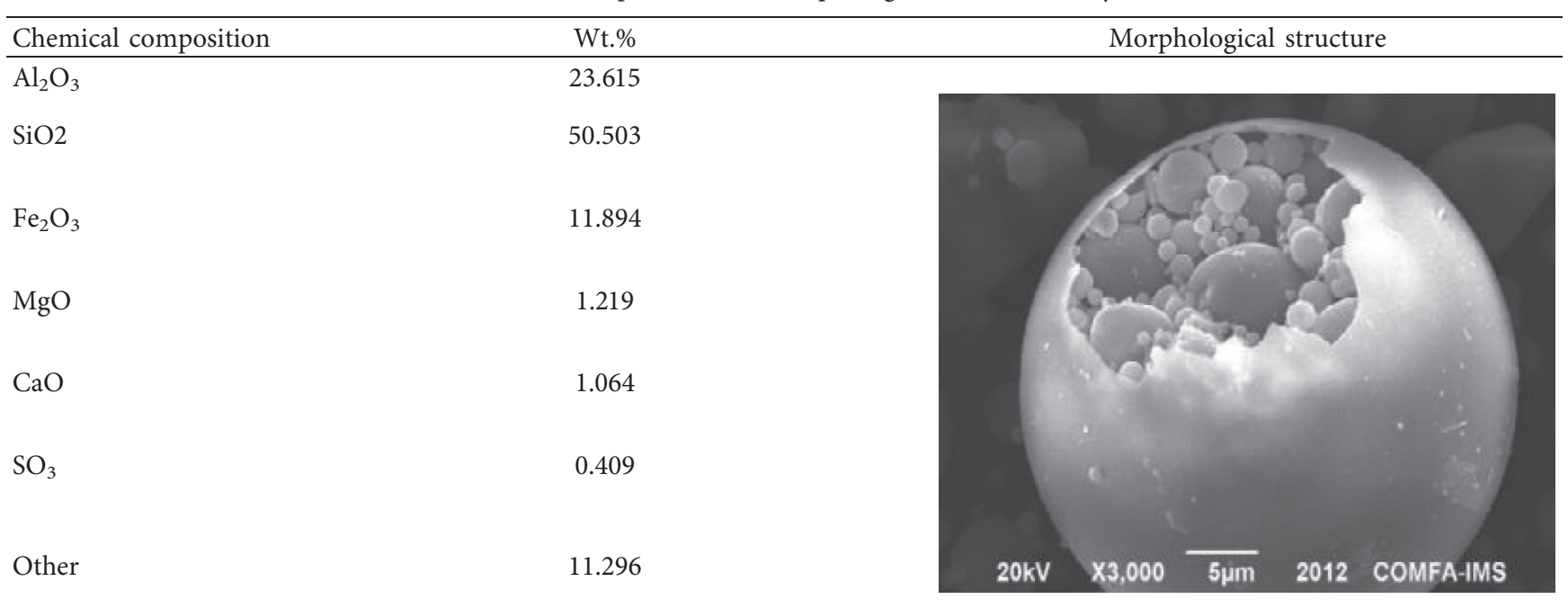

Scratch resistance: measured according to ISO 1518 on Erichsen tool model 239/I.

Determination of the adhesion of the paint film (TCVN 2097 - 1993).

Determination of flexural strength of paint films (TCVN 2099 - 1993).

Determination of the hardness of the paint film (ASTM D 3363 - 2011).

The UL 94 flame retardant and oxygen limit tests are conducted at the Polymer Materials Research Center, Hanoi University of Technology, Vietnam.

The morphology of the samples was carried out by scanning electron microscope (SEM, S4800, Japan).

\section{Results and Discussion}

\subsection{Mechanical Properties}

3.1.1. Evaluating the Results of the Coating Adhesion. Measuring the adhesion with the BEVS $2202 / 1^{\circ} \mathrm{C}$ paint film adhesion kit (China) for samples at different concentrations gave the following results (see Figure 1).

For all samples after testing the adhesion (each sample tested 3 times), it was found that there are small films peeling off at the intersection points, and the flaking area occupies not more than $5 \%$ of the surface area of the respective network with 2 points in the evaluation criteria. Since then, it
TABLE 3: Weight percentage of the coating.

\begin{tabular}{lccccccc}
\hline No. & APP & $\begin{array}{c}\text { Melamine } \\
\text { (mel) }\end{array}$ & PER & Epoxy & Hardener & MWCNTs & $\begin{array}{c}\text { Fly } \\
\text { ash }\end{array}$ \\
\hline F0 & 12.39 & 5.87 & 5.95 & 43.35 & 22.44 & 0 & 10 \\
F1 & 12.39 & 5.87 & 5.95 & 43.5 & 21.79 & 0.5 & 10 \\
F2 & 12.39 & 5.87 & 5.95 & 43.22 & 21.57 & 1 & 10 \\
F3 & 12.39 & 5.87 & 5.95 & 43.1 & 21.19 & 1.5 & 10 \\
F4 & 12.39 & 5.87 & 5.95 & 52.22 & 22.57 & 1 & 0 \\
\hline
\end{tabular}

shows that the adhesion of the coating is not at optimal level but has met the adhesion requirement.

3.1.2. Evaluating the Result of the Coating's Hardness. Hardness tests (conducted from pencil hardness $6 \mathrm{~B}$ to $6 \mathrm{H}$ ) for samples at different concentrations are shown in Figure 2.

The test results are evaluated as follows:

When the coating's surface has a hardness greater than that of a pencil, the pen will slide long over the surface without causing damage.

When the coating's surface is of a hardness equivalent to that of a pencil, the coating surface will be slightly scratched.

When the coating's surface has hardness less than pencil hardness, the coating surface will be severely damaged, depending on pencil hardness. 


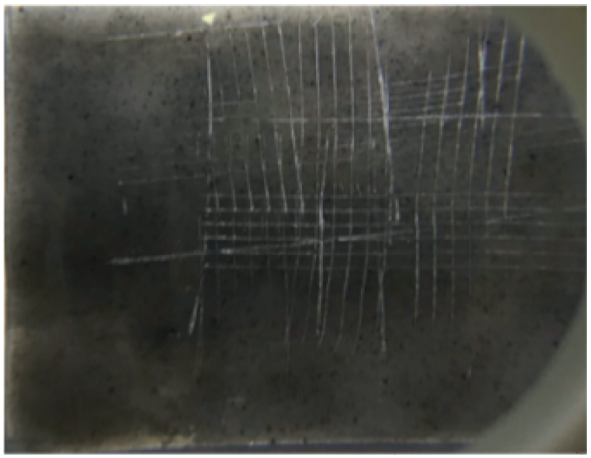

(a)

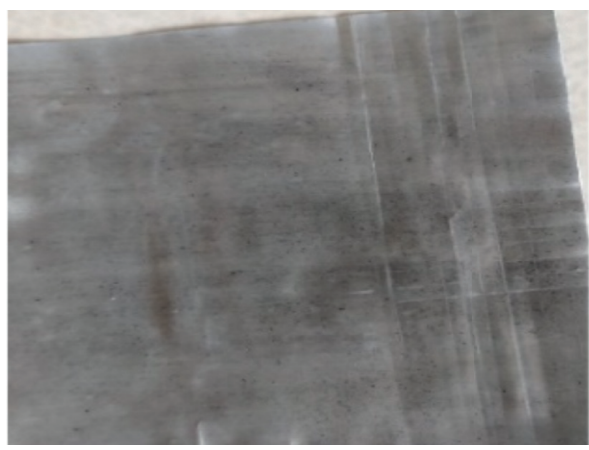

(c)

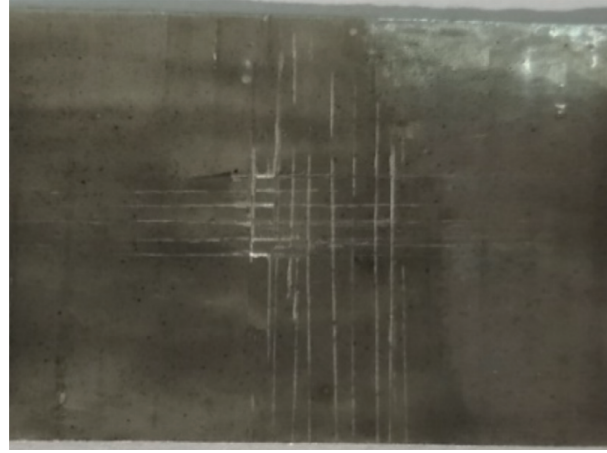

(b)

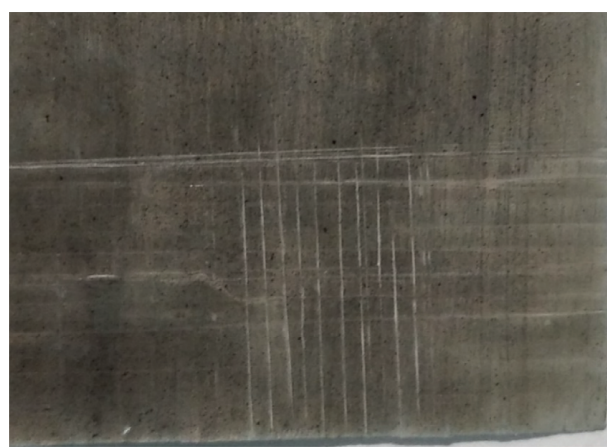

(d)

Figure 1: Sample after adhesion measurement (FA: Fly ash) (a) F1 (0.5 wt.\% MWCNTs, 10 wt.\% FA), (b) F2 (1 wt.\% MWCNTs, 10 wt.\% FA), (c) F3(1.5 wt.\% MWCNTs, 10 wt.\% FA), (d) F 4(1 wt.\% MWCNTs, 0 wt.\% FA).

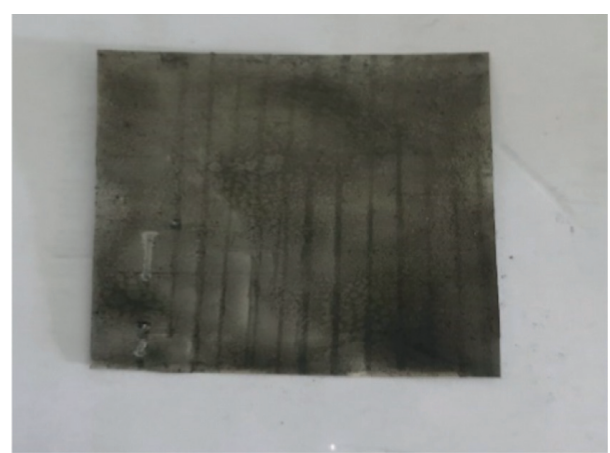

(a)

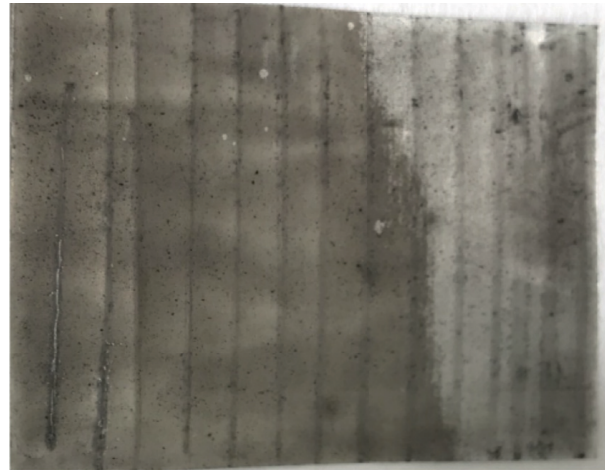

(c)

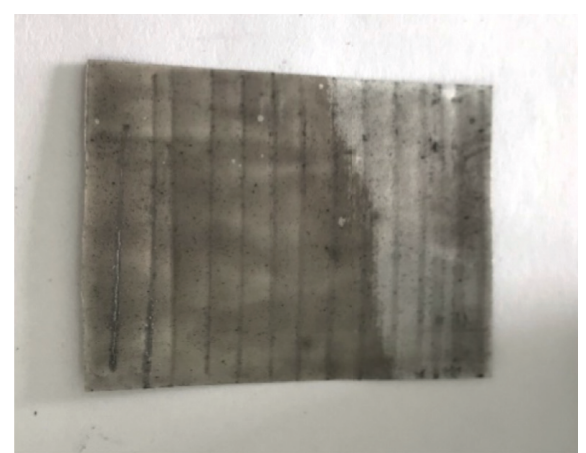

(b)

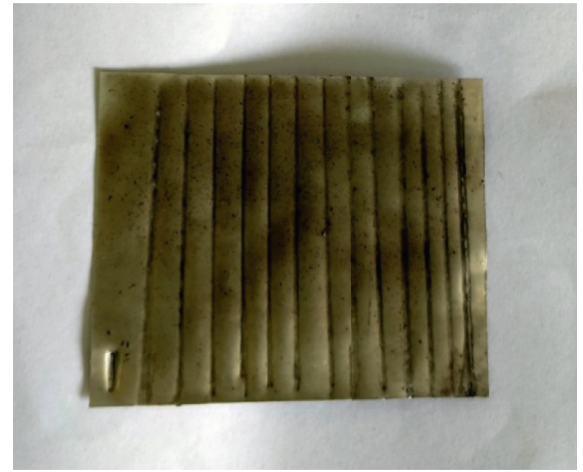

(d)

Figure 2: Samples after measuring the hardness. (a) F1 (0.5 wt.\% MWCNTs, 10 wt.\% FA). (b) F2 (1 wt.\% MWCNTs, 10 wt.\% FA). (c) F4 (1 wt.\% MWCNTs, 0 wt.\% FA). (d) F3 (1.5 wt.\% MWCNTs, 10 wt.\% FA). 
$(6 \mathrm{~B}-5 \mathrm{~B}-4 \mathrm{~B}-3 \mathrm{~B}-2 \mathrm{~B}-\mathrm{B}-\mathrm{HB}-\mathrm{F}-\mathrm{H}-2 \mathrm{H}-3 \mathrm{H}-4 \mathrm{H}-5 \mathrm{H}-6 \mathrm{H})$

Hard Soft

From Figure 2, it shows that all three samples (each sample tested 3 times) were severely damaged when the pencil of $6 \mathrm{H}$ hardness slid across the surface and was slightly scratched when the $5 \mathrm{H}$ hardness slipped across the surface; thus the coating's surface has a hardness equivalent to that of $5 \mathrm{H}$ hardness of pencil.

Based on the hardness scale, all three samples have a hardness corresponding to the $5 \mathrm{H}$ hardness of the pencil, showing that the film samples coated on epoxy substrate in the presence of fly ash and multi-wall carbon nanotubes have very stiffness high.

3.1.3. Evaluating the Results of the Flexural Strength of the Coating. The flexural strength of the film is expressed as the diameter of the smallest cylindrical shaft, on which the coating has not deformed. Record the diameter of the first deformed batch, and repeat the test of the same size three times on new sheets, the average result being the end result to be obtained. Figure 3 shows the flexural strength results of the cylindrical shafts with diameters of $2,3,4,5,6,8,10,12,13,16,19,20,25$, and $32 \mathrm{~mm}$ included in the hinge set. These samples were carried out using the same method with the test sample at different volumes. From Figure 3, on the set of coating flexural test hinges, at a cylindrical shaft with a minimum diameter of $2 \mathrm{~mm}$, all three test pieces are undistorted, showing the flexural strength of the three respective test pieces with a minimum shaft diameter of $2 \mathrm{~mm}$, meeting good flexural strength requirements for epoxy-based films in the presence of fly ash and multi-wall carbon nanotubes.

\subsection{Flame Retardant Properties of the Coating}

3.2.1. Tested according to Method UL $94 \mathrm{HB}$ and LOI. From Figure 4, the results of the dispersion of MWCNTs into the epoxy binder clearly have an effect on the improved fire resistance of the coating. When the combustible material MWCNTs form uniform and sealed coal coatings on the surface of the material, it slows down the diffusion of oxygen, thus preventing the development of the fire. The formation of a layer of coal (ash) spread evenly on the surface of the material prevents the penetration of the fire and helps extinguish the burning process. This proves that the fire resistance of the material is significantly improved. Thanks to the properties of the flame retardant mechanism, the flame retardant properties of the material have been improved. Two samples of flame retardant coating F2, F3 are evaluated to achieve $\mathrm{HB}$ level through the horizontal fire method according to UL 94 standard; both samples stop burning before $25 \mathrm{~mm}$ mark after $30 \mathrm{~s}$ ignition time (see Figure 5). For F2 sample, the coating after the ignition does not ignite but forms a coal layer and shows good fire resistance and conditions for assessment according to the vertical fire standard. The results of the process of dispersing MWCNTs into epoxy clearly affected the improved fire resistance of the nanocomposite coating. A barrier-like protective layer made up of nanoparticles that are inherently heat-resistant and hold heat slows down oxygen diffusion and prevents flammable volatiles from within the material, limiting the heat transfer to the material thus reducing the retention time of the combustion. But if the MWCNTs content exceeds the threshold (1.5\% mass fraction) leading to a decrease in the compatibility with epoxy resin and the accumulation of nanoparticles, the excess nanoparticles create holes in the main material. This factor is responsible for the reduction of the mechanical strength compared to the $1 \%$ nano-mass sample. Thus, $1 \%$ of MWCNTs is the most suitable content for epoxy resin-based nanocomposite coating to ensure high fire retardation.

Tested according to method UL $94 \mathrm{~V}$, the flame retardancy of the coating film is further evaluated by the UL9 $4 \mathrm{~V}$ method; the results are presented in Table 4.

Table 4, shows that the nanocomposite coatings with fire retardant additives including nano- and basic constituents have a good fire resistance. Total burning time $(t 1+t 2)$ of three samples (F1, F2, F3) reach Vo level $(\mathrm{t} 1+\mathrm{t} 2 \leq 50 \mathrm{~s})$. Obviously, MWCNTs played a very important role in enhancing the fire resistance of the coatings and the optimum amount of MWCNTs is 1 wt.\%.

From the flammability test results between two samples F2, F3 and the steel surface of the two samples when peeling off the coating after fire (Figure 6), it shows the fire resistance of the sample presents fly ash additive and multi-walled nanocarbon tubes achieve very high efficiency. For sample F3, after the sample burns, a hard coal layer formed by the presence of fly ash and multi-walled nanocarbon tubes increases heat resistance. For F2 sample, the sample does not burn after ignition but creates a layer of coal that swells thanks to the presence of a mixture of flame retardant additives (APP, PER, melamine) and another layer of coal formed by multi-wall nanocarbon tubes making F2 model has a superior ability to prevent combustion compared to F3.

In Figure 7, after burning, on the coating surface there is a blister layer of coal; this layer of coal is examined under the scanning electron microscope (SEM); Figure 7(b) shows that the coal layer is swelling. It has a variety of small pore structures such as foam in the coal-coating structure of the coating, thereby explaining the water-loss reaction mechanism of PER to make coal and the gaseous mechanism of melamine compounds in a temperature range fit. Furthermore, the swelling coal layer has a small pore structure that creates a high insulation effect for the protective material, and the interaction of fly ash additive and multi-wall nanocarbon pipes not only enhances the mechanical properties of the coating but also has the ability to retard the coating film on metal surfaces.

\subsection{Mechanical Properties of the Nanocomposite Coating.} The mechanical properties of the nanocomposite coating with different MWCNTs: $0.5 \%, 1 \%, 1.5 \%$ by volume, are presented in Figure 8. From Figure 8, it was found that the MWCNTs content in epoxy increased, and the mechanical strength increased. However, when increasing up to $1.5 \%$ of MWCNTs, the increase in mechanical strength is not high compared to that of the material when adding $1 \%$ of MWCNTs. Samples containing $1 \%$ by weight of MWCNTs are relatively more resistant to impact, tensile strength, 


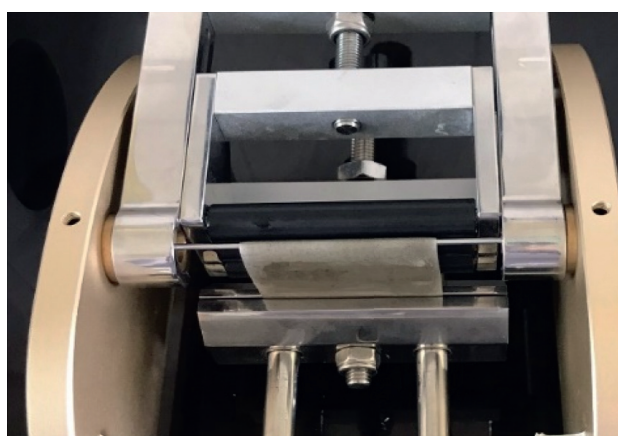

(a)

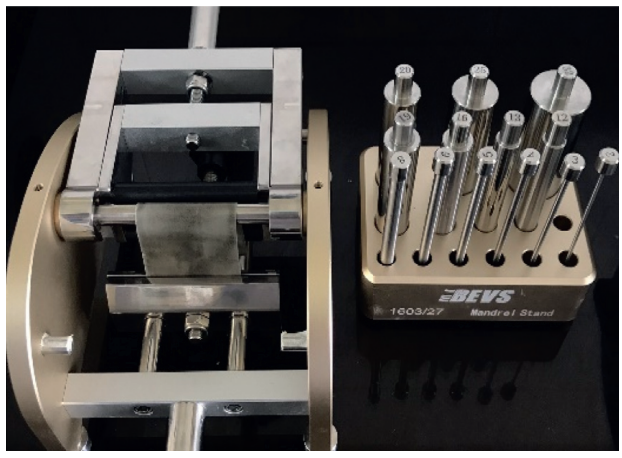

(c)

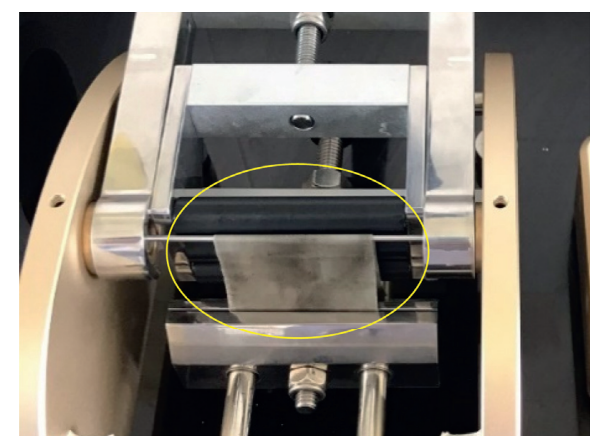

(b)

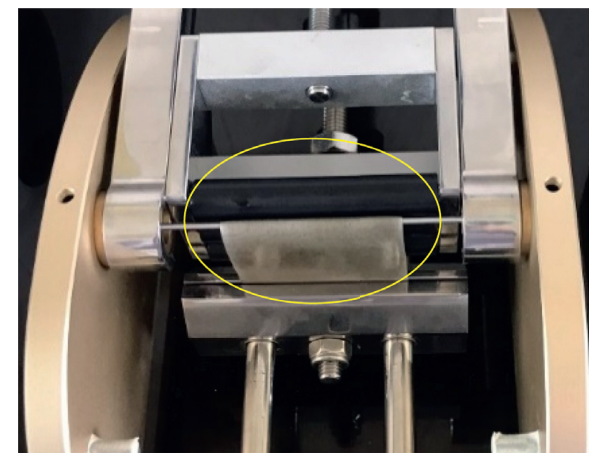

(d)

FIGURE 3: Image of flexural strength measurement of coating materials: (a) F1 ( 0.5 wt.\% MWCNTs, 10 wt.\% FA). (b) F2 (1 wt.\% MWCNTs, 10 wt.\% FA). (c) F4 (1 wt.\% MWCNTs, 0 wt.\% FA). (d) F3 (1.5 wt.\% MWCNTs, 10 wt.\% FA).
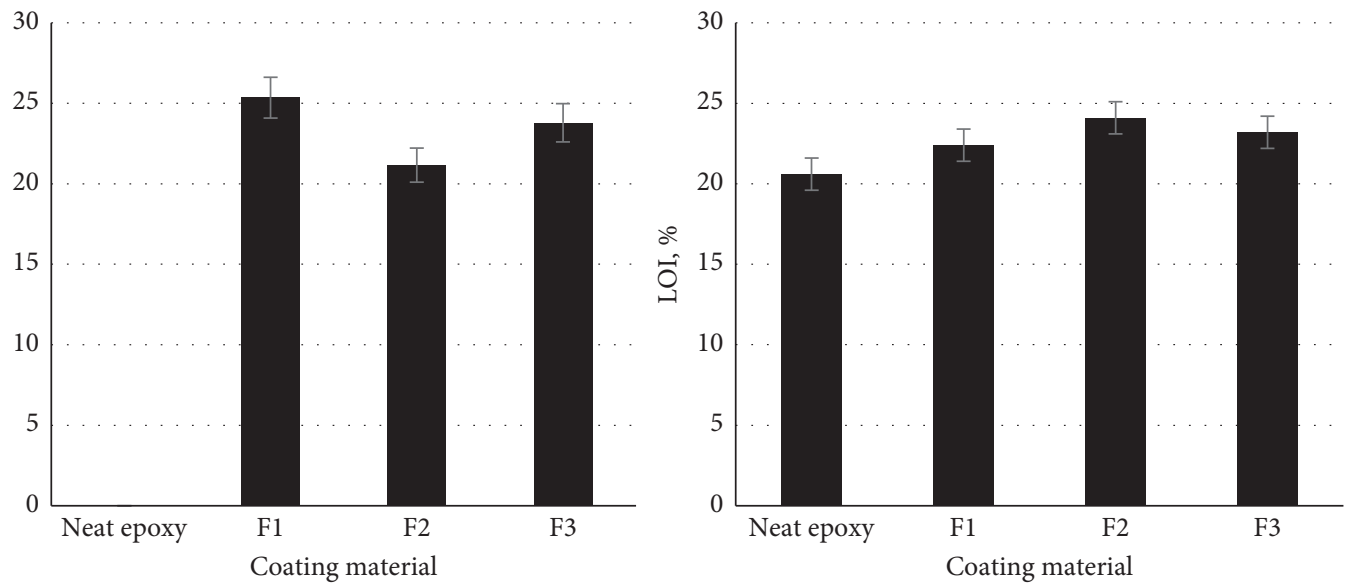

FIGURE 4: Fire retardant properties of the coating material based on epoxy resin with multi-wall carbon nanoadditive.

scratch resistance, and durability than models with $0.5 \%$ by weight and $1.5 \%$ by weight of MWCNTs. To study the cause of increasing the mechanical strength of the material, SEM (Figure 9) was performed on the fractured surface, showing different fracture surface with different rates of MWCNTs (0.5, 1, and 1.5 wt.\%).

SEM images (Figure 9) show fairly uniform dispersion for samples added with $1 \%$ mass of MWCNTs, and agglomeration of MWCNTs in the resin occurs when dispersion is greater than $1.5 \%$ by mass MWCNTs. The fracture surfaces of the nanocomposite coating showed resistance to the brittleness of carbon nanotubes. This indicates that strong adhesion takes place between MWCNTs and epoxy E 240, and good compatibility with flame retardant additives (ammonium polyphosphate (APP)/pentaerythritol (PER), and melamine). The MWCNTs play an important role in limiting fracture development (Figure 9) and require greater applied force.

Coarse fracture surface may show enlarged cracks due to crack blocked by polymer networks and MWCNTs as the applied force increases. Make the development trajectory of the crack altered. Therefore, the mechanical strength of the coating is significantly improved in the. On the other hand, due to the nanoadditive dispersion and good compatibility in the system, the fire resistance is enhanced, because the 

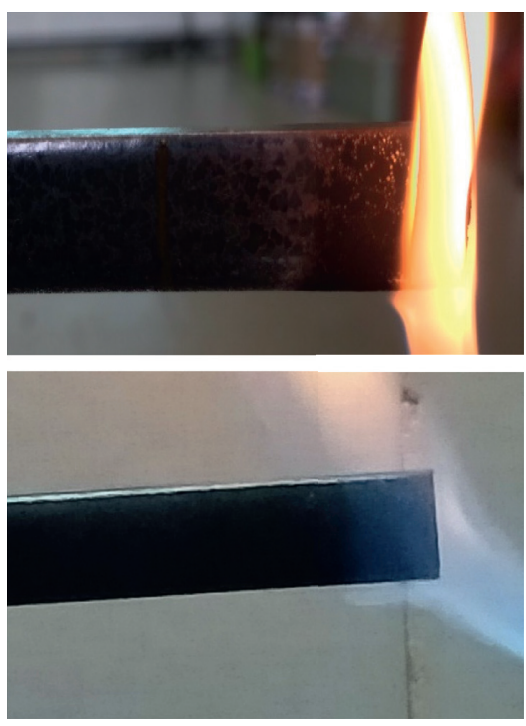

(a)
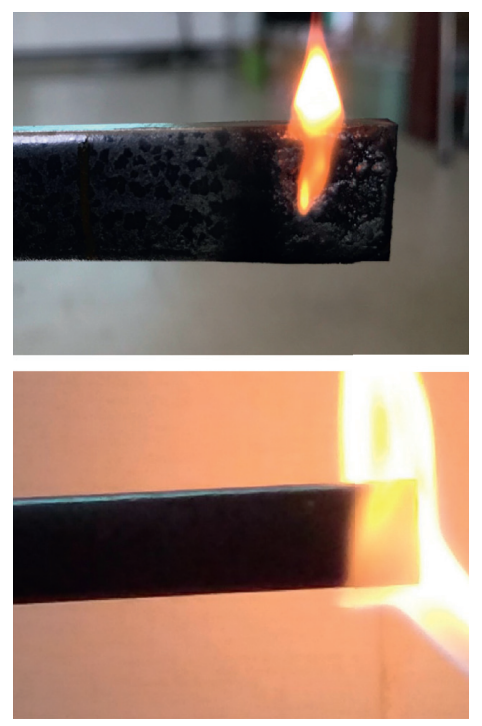

(b)
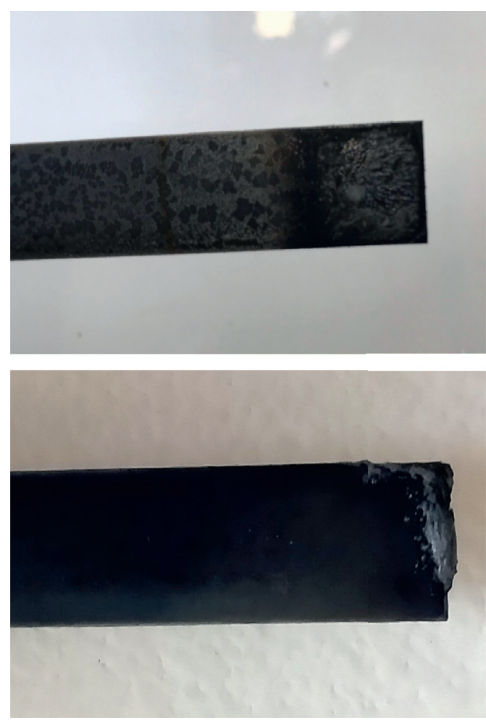

(c)

Figure 5: Flame retardant test samples according to UL 94 HB. (a) F1 (0.5 wt.\% MWCNTs, 10 wt.\% FA). (b) F3(1.5 wt.\% MWCNTs, 10 wt.\% FA). (c) F2 (1 wt.\% MWCNTs, 10 wt.\% FA).

TABLE 4: Total burning time $\left(t_{1}+t_{2}\right)$ of the nanocomposite coating.

\begin{tabular}{lccc}
\hline Sample & Content of MWCNTs, (wt.\%) & Burning time $\left(t_{1}+t_{2}\right)$, seconds $(S)$ & UL 94 V rated \\
\hline F0 & 0 & 55.12 & $\mathrm{~V}_{1}$ \\
F1 & 0.5 & 14.29 & $\mathrm{~V}_{0}$ \\
F2 & 1.0 & 12.02 & $\mathrm{~V}_{0}$ \\
F3 & 1.5 & 13.50 & $\mathrm{~V}_{0}$ \\
\hline
\end{tabular}
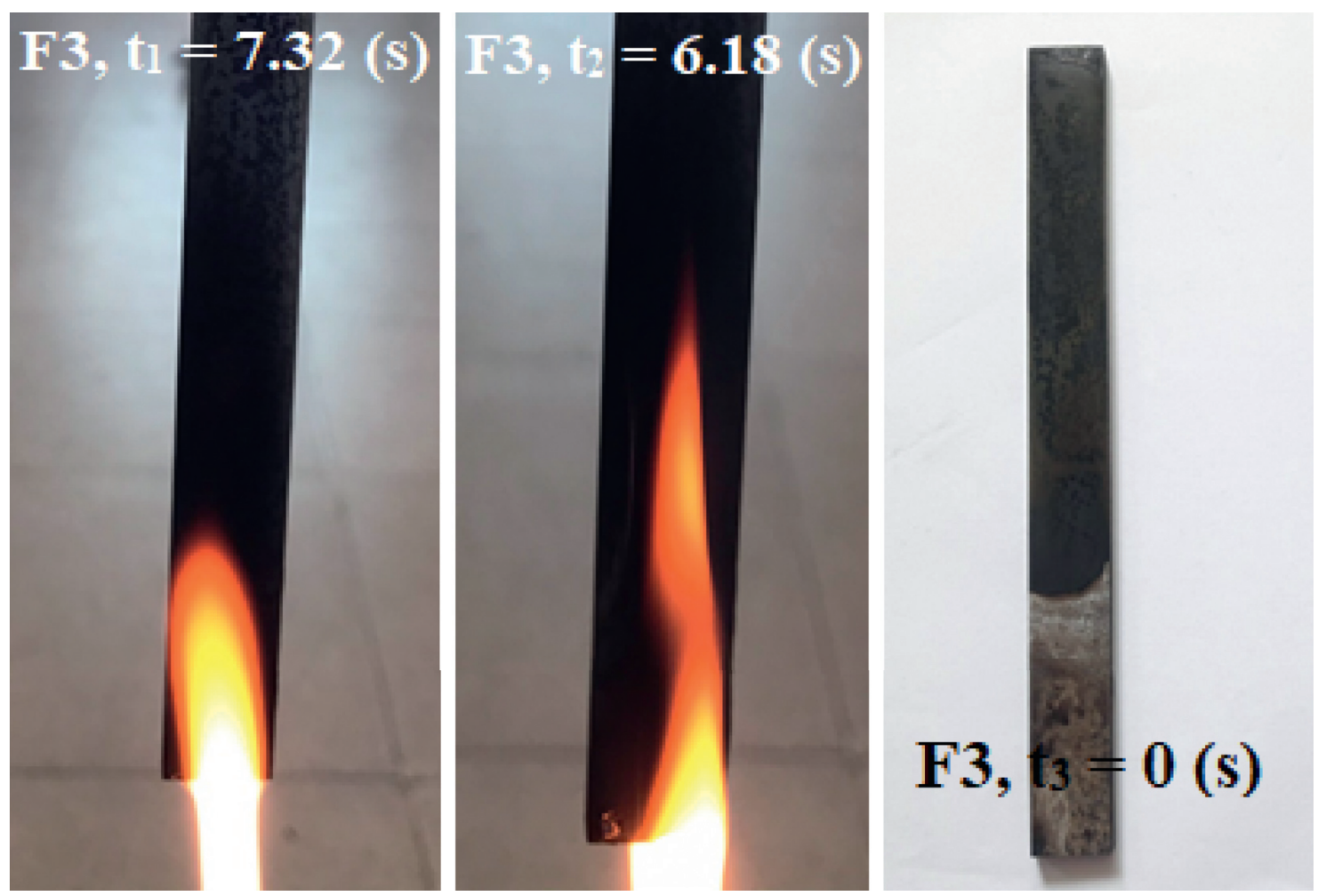

(a)

Figure 6: Continued. 

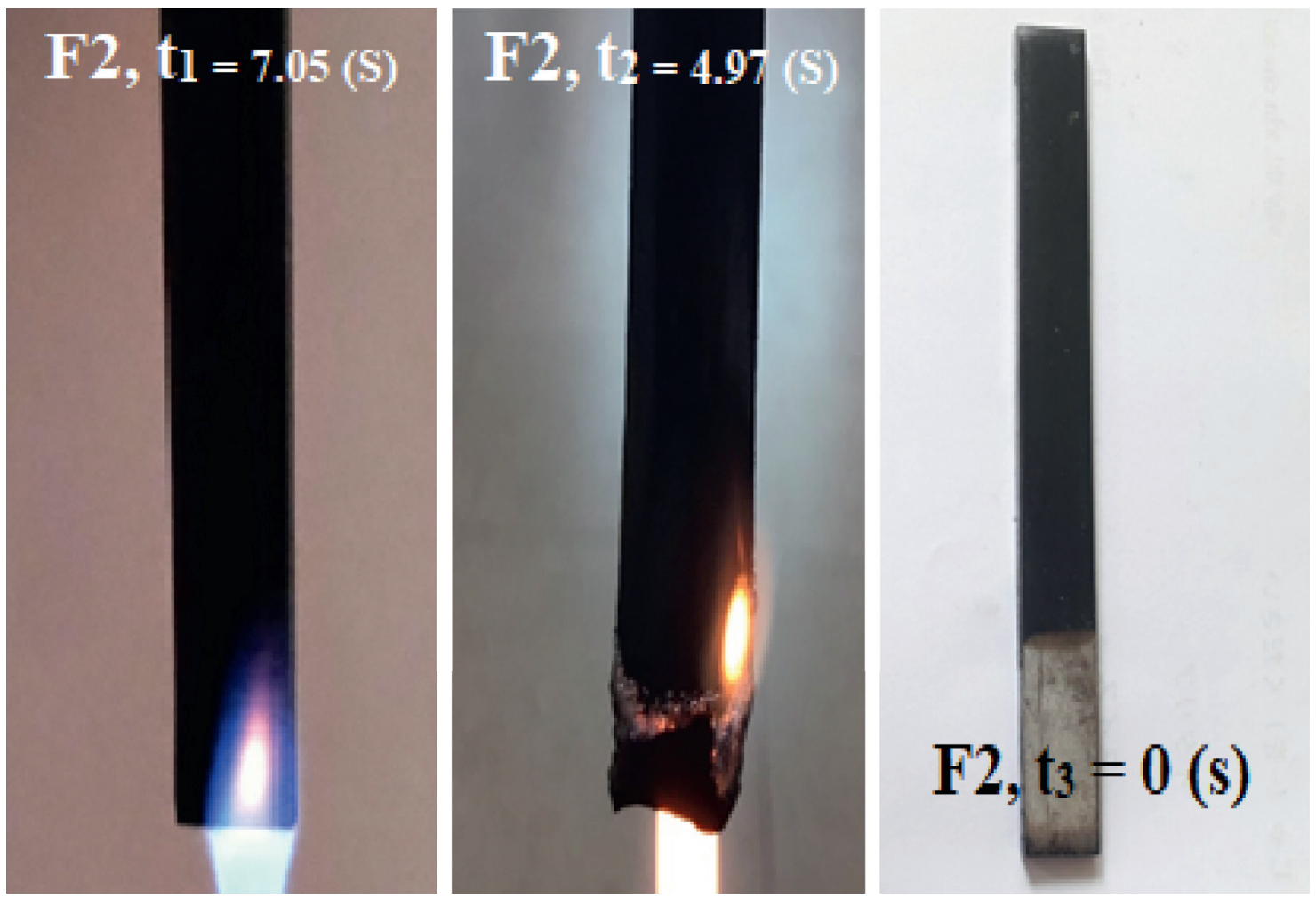

(b)

Figure 6: Test image of coating according to UL $94 \mathrm{~V}$ method and surface of steel after burning. (a) F3(1.5 wt.\% MWCNTs, 10 wt.\% FA). (b) F2 (1 wt.\% MWCNTs, 10 wt.\% FA).

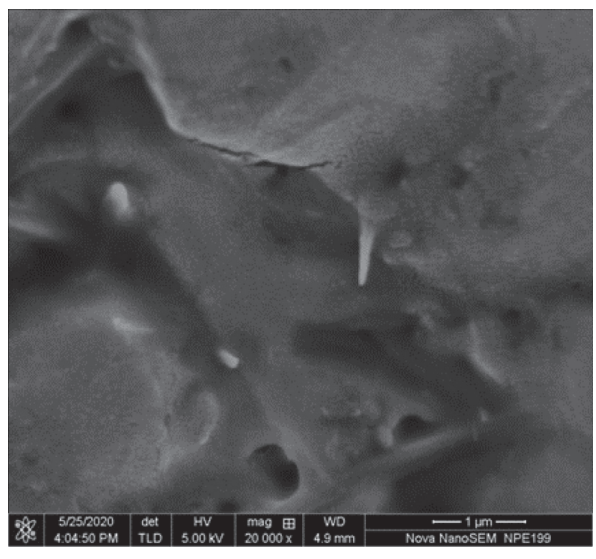

(a)

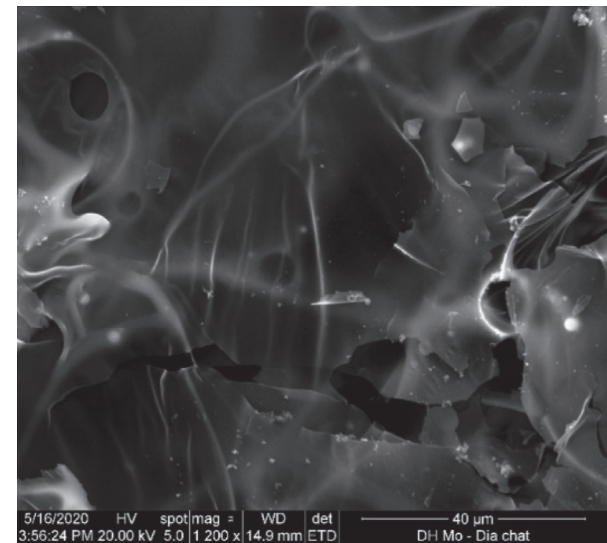

(b)

Figure 7: Continued. 


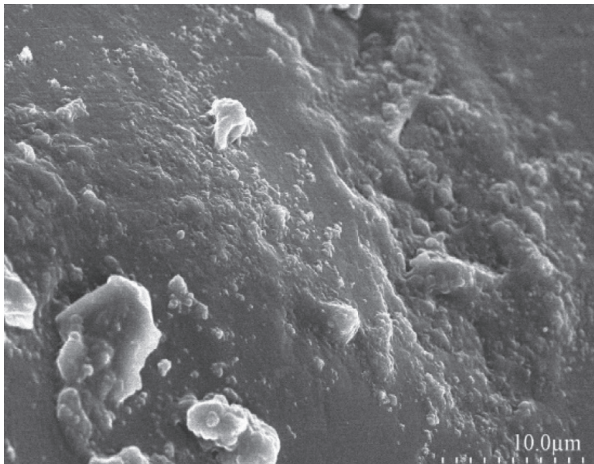

(c)

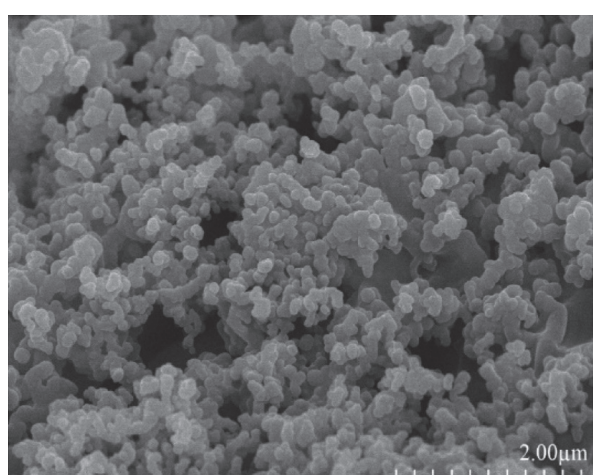

(d)

Figure 7: The results of SEM imaging of the coating surface after burning. (a) F3 (1.5 wt.\% MWCNTs, 10 wt.\% FA). (b) F2 (1 wt.\% MWCNTs, 10 wt.\% FA). (c) F4 (1 \% wt.\% MWCNTs, 0 wt.\% FA). (d) F1: neat epoxy.
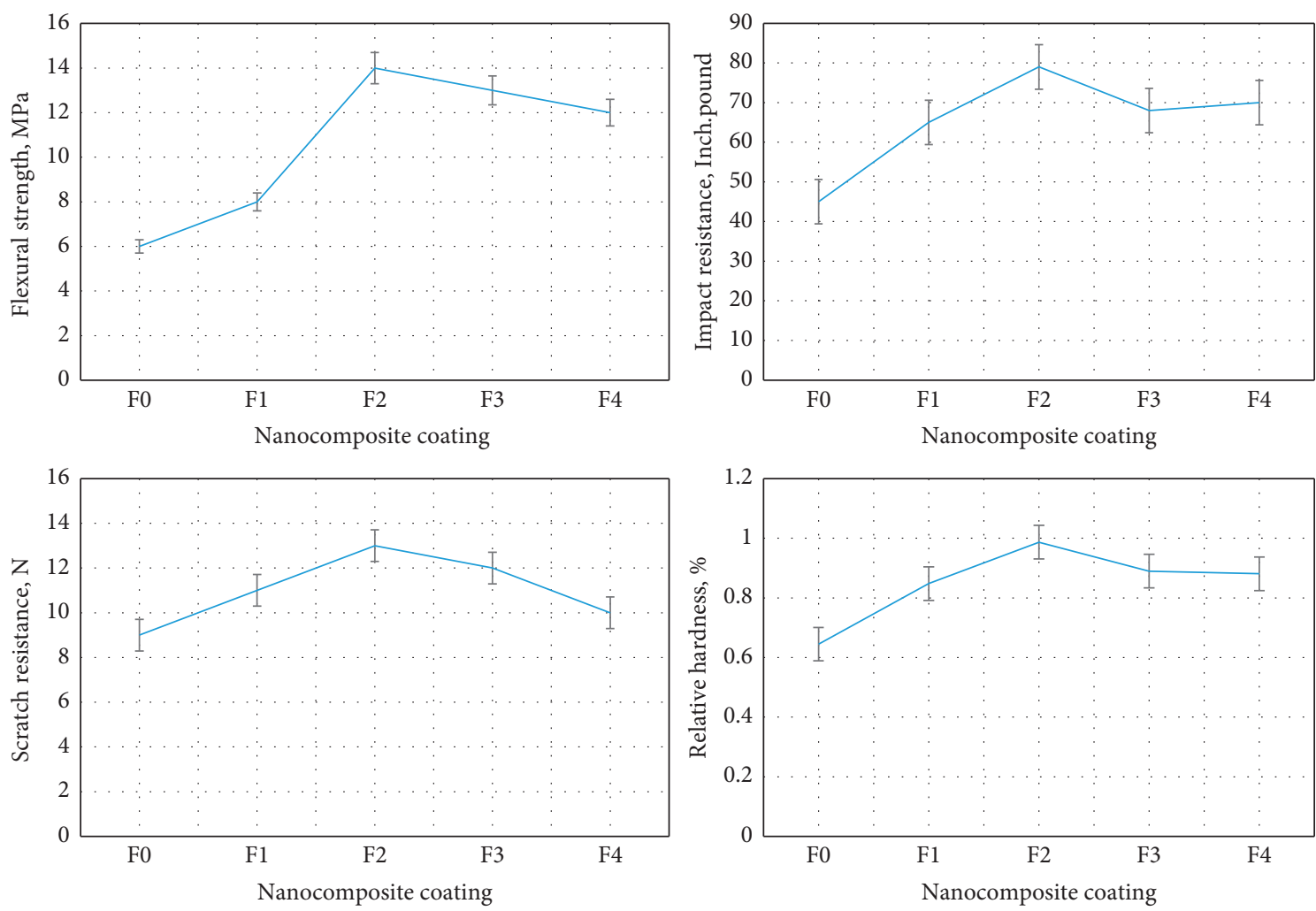

FIGURE 8: Mechanical properties of the nanocomposite coating.

protective layer by the effect of heat will be uniform and widely distributed. This is very consistent with the results of the measurement of mechanical properties and flame retardant properties above.

Figure 10, taken at different points on the mantle fracture surface, shows that the additives are evenly dispersed and show very clear wetting and bonding with epoxy paints. Evidence shows that, after the material is broken, fly ash particles remain on the fracture surface and epoxy surrounds the grain (no gaps around the grain). In that gas, MWCNTs are also distributed evenly and creep into the area of flame retardant additives; there is no phenomenon of clumping and agglomeration, showing good compatibility of the combination MWCNTs-flame retardantsepoxy.

3.4. FTIR Analysis. The coal residues were analyzed using spectroscopic tools to understand the mechanism of the interaction between EG, APP, melamine, boric acid, epoxy, and hardener. The FTIR spectrum of equations F1, F2, F3, and F0 are shown in Figure 11.

From the results of the infrared spectrum of Figure 11, we can see on the spectrum areas of the following groups: 


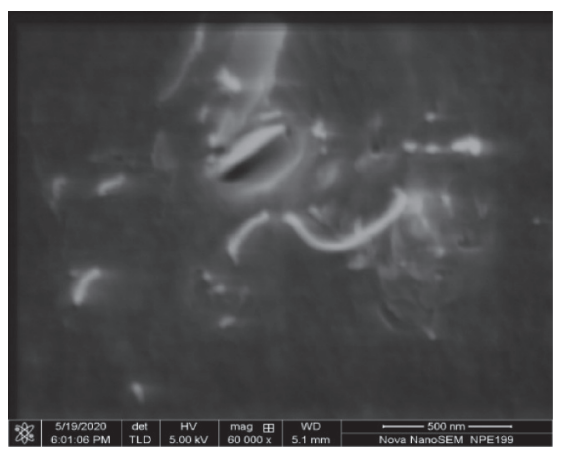

(a)

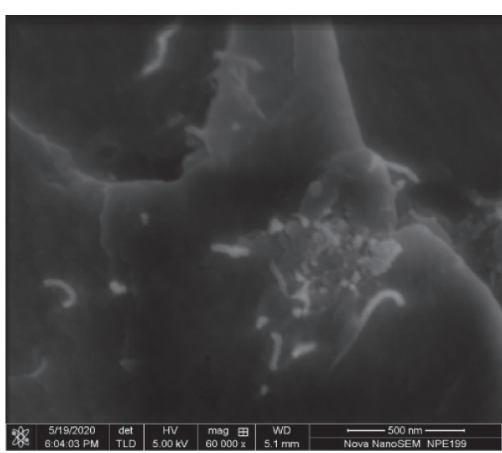

(b)

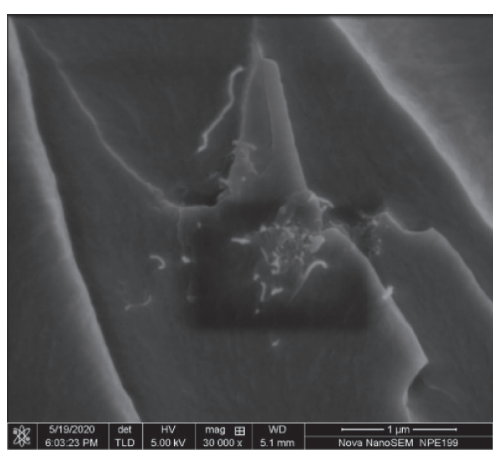

(c)

FiguRE 9: Structural morphology of the nanocomposite coating. (a) F3(1 \% wt.\% MWCNTs, 10 wt.\%FA). (b) F2 (1 wt.\% MWCNTs, 10 wt.\% FA). (c) F2 (0.5 wt.\% MWCNTs, 10 wt.\% FA).
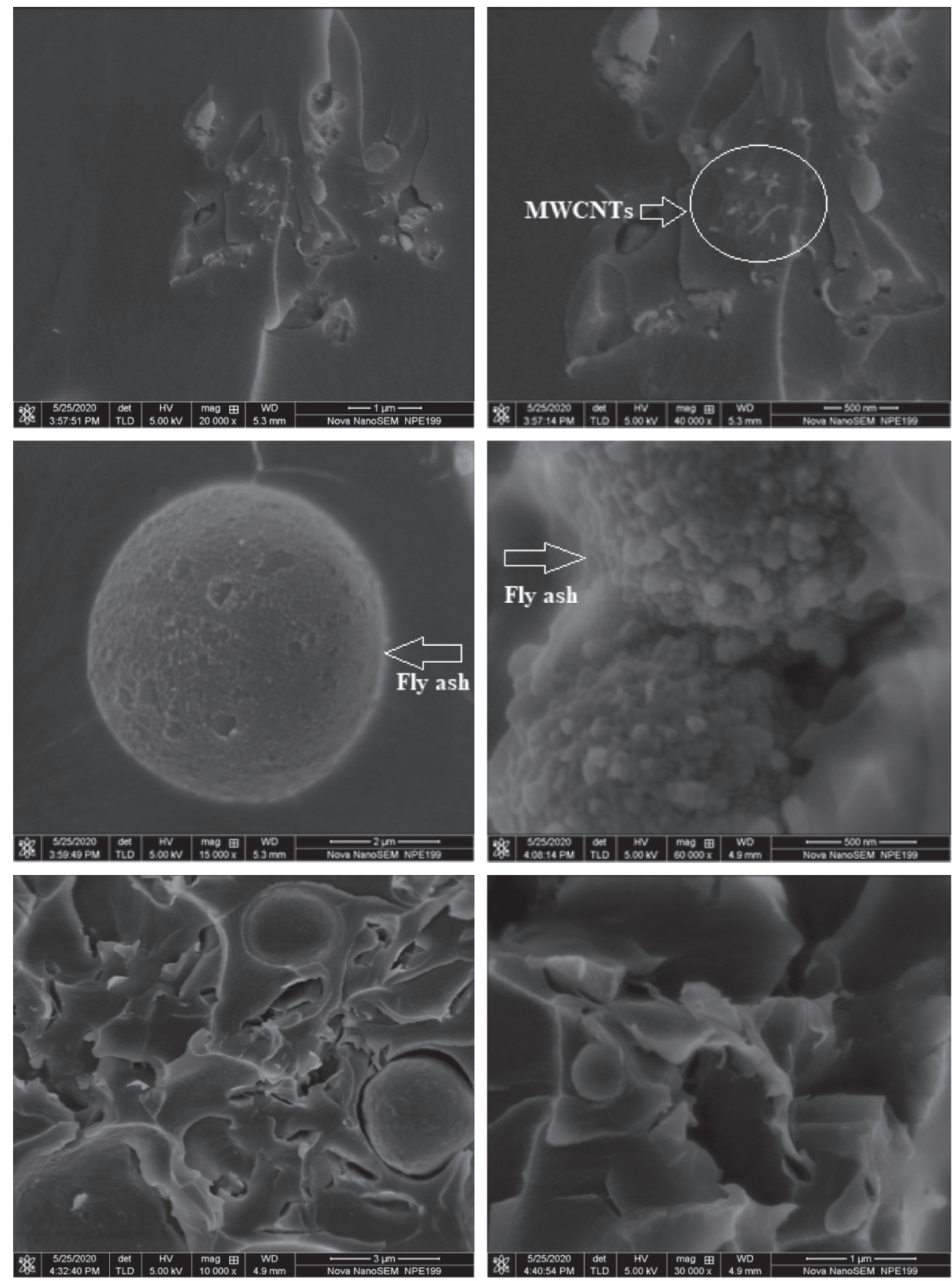

FIGURE 10: Image of the fractured surface structure of the coating with 1 wt.\% MWCNTs, 10 wt.\% FA in different regions. 


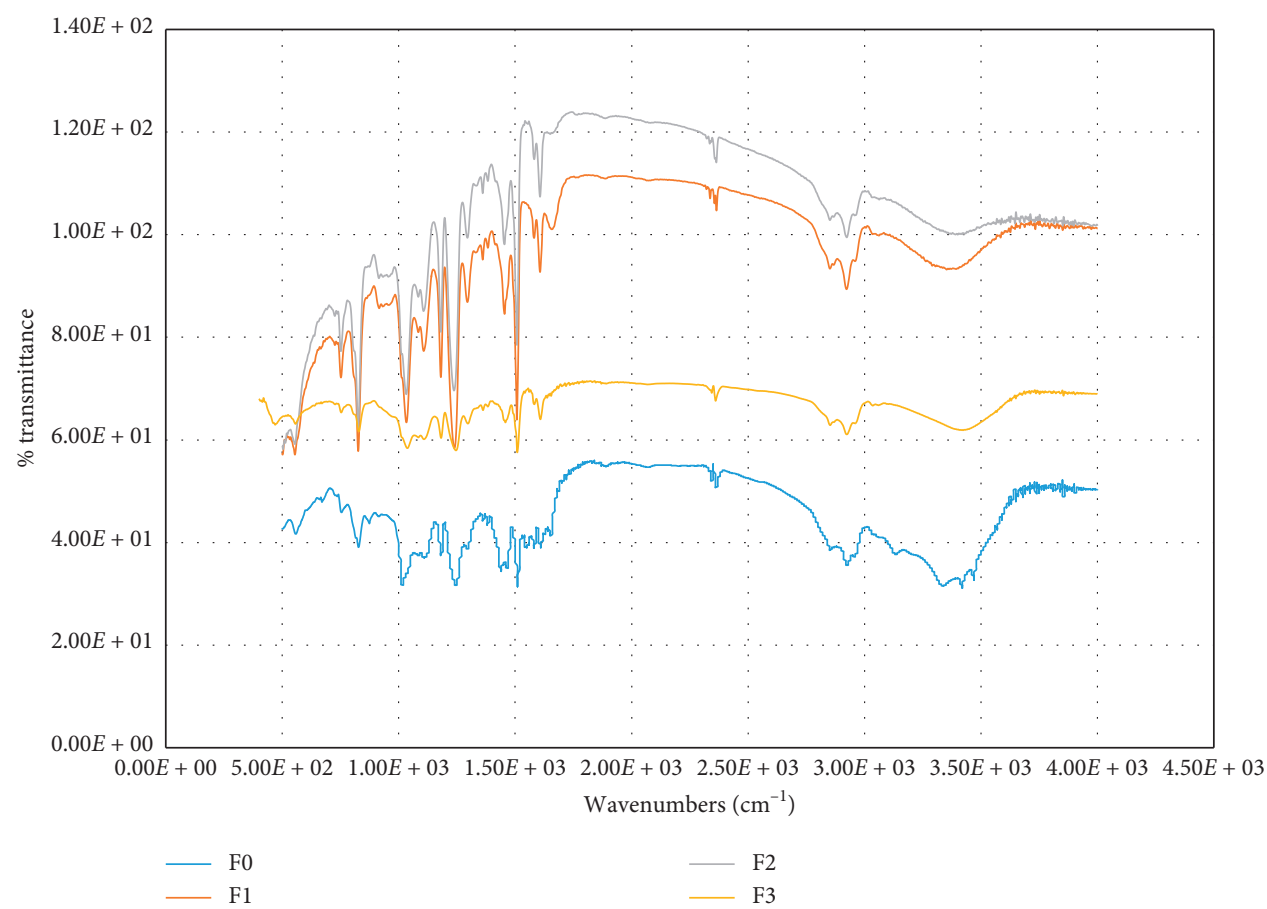

Figure 11: FTIR spectra of formulation F0, F1, F2, and F3 (F0: the coating consisted of the absence of MWCNTs, F1: 0.5 wt.\% MWCNTs, F2: 1 wt.\% MWCNTs and F3: 1.5 wt.\% MWCNTs).

amines $\left(\mathrm{NH}_{2}\right)$, borate, phosphate, and melamine. The presence of amino groups is due to breakdown of APP and polyamide hardener.

\section{Conclusions}

The results of this study show that melamine and boric acids, MWCNTs, and fly ash contribute to improving the insulation properties of the materials but each has its own way.

Based on the results of melamine-containing formulations, we infer that melamine acts as a blowing agent and helps coal expansion.

The results in this work show that the reactive products of melamine are degraded, while the boric acid remains in charcoal and protects the substrate from fire. When the percentage weight of boric acid has been increased for melamine in the formulation, the fire protection performance is improved.

SEM results show that the structure of excess coal becomes porous when the percentage weight MWCNTs has increased; the best result is 1wt.\% MWCNTs. MWCNTs created a protective barrier like an insulating coal layer. Therefore, the heat flow has decreased to the substrate, and this reduces rear surface temperature.

FTIR shows the presence of graphite, phosphate, and $\mathrm{B}_{2} \mathrm{O}_{3}$ in residual coal. These compounds are useful in lowering the temperature of the back panel because of their high thermal stability.

The results demonstrate that the addition of fly ash to the coating material has a synergistic effect against fire with other additives. This is an industrial waste. The properties of fly ash are useful and can contribute to the organic coating sector.

\section{Data Availability}

The experimental data used to support the findings of this study are included within the article.

\section{Conflicts of Interest}

The author declares no conflicts of interest.

\section{Acknowledgments}

The author wishes to thank the Faculty of Chemical Technology, Hanoi University of Industry, Vietnam, for funding this work.

\section{References}

[1] S. Ullah, F. Ahmad, A. M. Shariff, and M. A. Bustam, "Synergistic effects of kaolin clay on intumescent fire retardant coating composition for fire protection of structural steel substrate," Polymer Degradation and Stability, vol. 110, pp. 91-103, 2014.

[2] S. Ullah, F. Ahmad, and P. S. M. Megat Yusoff, "Effect of boric acid and melamine on the intumescent fire-retardant coating composition for the fire protection of structural steel substrates," Journal of Applied Polymer Science, vol. 128, pp. 1-11, 2012.

[3] K. Muralishwara, U. Achutha Kini, and S. Sharma, "Epoxyclay nanocomposite coatings: a review on synthesis and 
characterization," Materials Research Express, vol. 6, pp. 1-9, 2019.

[4] E. N. E. Dahalan, A. H. Sofian, A. Abdullah, and N. M. Noor, "Corrosion behavior of organic epoxy-xinc coating with fly ash as an extender pigment," Materials Today: Proceedings, vol. 5, pp. 21629-21635, 2018.

[5] T. A. Nguyen, Q. T. Nguyen, X. C. Nguyen, and V. H. Nguyen, "Study on fire resistance ability and mechanical properties of composites based on Epikote 240 Epoxy Resin and thermoelectric fly ash: an ecofriendly additive," Journal of Chemistry, vol. 2019, Article ID 2635231, 8 pages, 2019.

[6] T. A. Nguyen, "Effects of the amount of fly ash modified by stearic acid compound on mechanical properties flame retardant ability, and structure of the composites," International Journal of Chemical Engineering, vol. 2020, Article ID 2079189, 6 pages, 2020.

[7] T. A. Nguyen and Q. T. Nguyen, "Study on synergies of fly ash with multiwall carbon nanotubes in manufacturing fire retardant epoxy nanocomposite," Journal of Chemistry, vol. 2020, Article ID 6062128, 9 pages, 2020.

[8] T. A. Nguyen and T. M. H. Pham, "Study on the properties of epoxy composites using fly ash as an additive in the presence of nanoclay: mechanical properties, flame retardants, and dielectric properties," Journal of Chemistry, vol. 2020, Article ID 8854515, 11 pages, 2020.

[9] T. A. Nguyen, Q. T. Nguyen, and T. P. Bach, "Mechanical properties and flame retardancy of epoxy resin/nanoclay/ multiwalled carbon nanotube nanocomposites," Journal of Chemistry, vol. 2019, Article ID 3105205, 9 pages, 2019.

[10] T. A. Nguyen, "Mechanical and flame-retardant properties of nanocomposite based on epoxy resin combined with epoxidized linseed oil, which has the presence of nanoclay and MWCNTs," Journal of Chemistry, vol. 2020, Article ID 2353827, 8 pages, 2020.

[11] R. H. Raymond, "Historical Aspects of Polymer Fire Retardance," Fire and Polymers, vol. 7, pp. 87-96, 1990.

[12] J. R. Lawson, "A history of fire testing," NIST Technical Note, vol. 1628, pp. 11-12, 2009.

[13] S. Bourbigot and S. Duquesne, "Fire retardant polymers: recent developments and opportunities," Journal of Materials Chemistry, vol. 17, no. 22, pp. 2283-2300, 2007.

[14] S. Bourbigot, S. Duquesne, and J.-M. Leroy, "Modeling of heat transfer of a polypropylene-based intumescent system during combustion," Journal of Fire Sciences, vol. 17, no. 1, pp. 42-56, 1999.

[15] G.-Q. Li, C. Zhang, G.-B. Lou, Y.-C. Wang, and L.-L. Wang, "Assess the fire resistance of intumescent coatings by equivalent constant thermal resistance," Fire Technology, vol. 48, no. 2, pp. 529-546, 2012.

[16] S. Huo, P. Song, B. Yu et al., "Phosphorus-containing flame retardant epoxy thermosets: recent advances and future perspectives," Progress in Polymer Science, vol. 114, Article ID 101366, 2021.

[17] W. He, P. Song, B. Yu, Z. Fang, and H. Wang, "Flame retardant polymeric nanocomposites through the combination of nanomaterials and conventional flame retardants," Progress in Materials Science, vol. 114, Article ID 100687, 2020.

[18] H. Yu, J. Liu, X. Wen et al., "Charing polymer wrapped carbon nanotubes for simultaneously improving the flame retardancy and mechanical properties of epoxy resin," Polymer, vol. 52, Article ID 4891e4898, 2011.

[19] B. Dittrich, K. A. Wartig, D. Hofmann, R. Mülhaupt, and B. Schartel, "Flame retardancy through carbon nanomaterials: carbon black, multiwall nanotubes, expanded graphite, multi- layer graphene and graphene in polypropylene," Polymer Degradation and Stability, vol. 98, Article ID 1495e1505, 2013.

[20] S. S. Rahatekar, M. Zammarano, S. Matko et al., "Effect of carbon nanotubes and montmorillonite on the flammability of epoxy nanocomposites," Polymer Degradation and Stability, vol. 95, Article ID 870e879, 2010.

[21] S. I. Ji, K. L. Sung, J. I. Se, and S. L. Young, "Improved flame retardant properties of epoxy resin by fluorinated MMT/ MWCNT additives," Journal of Analytical and Applied Pyrolysis, vol. 89, pp. 225-232, 2010.

[22] L. Xu, Z. Fang, P. a. Song, and M. Peng, "Functionalization of carbon nanotubes by corona-discharge induced graft polymerization for the reinforcement of epoxy nanocomposites," Plasma Processes and Polymers, vol. 7, no. 10, pp. 785-793, 2010.

[23] H. Ma, P. Song, and Z. Fang, "Flame retarded polymer nanocomposites: development, trend and future perspective," Science China Chemistry, vol. 54, no. 2, pp. 302-313, 2011.

[24] P. A. Song, L. Xu, Z. Guo, Y. Zhang, and Z. Fang, "Flameretardant-wrapped carbon nanotubes for simultaneously improving the flame retardancy and mechanical properties of polypropylene," Journal of Materials Chemistry, vol. 18, no. 42, pp. 5083-5091, 2008.

[25] S. Ran, F. Fang, Z. Guo et al., "Synthesis of decorated graphene with $\mathrm{P}, \mathrm{N}$-containing compounds and its flame retardancy and smoke suppression effects on polylactic acid," Composites Part B: Engineering, vol. 170, pp. 41-50, 2019.

[26] P. Bachtrong, L. Nguyenthanh, and H. Phamthi, "Effect of fly ash from thermal power plant on the dielectric properties of polymer composites materials based on matrix epoxy DER 331," Chemical Engineering Transactions, vol. 56, pp. 12071212, 2017. 